\title{
Impact of Intervention on the Reproductive Health Knowledge of Adolescent Girls from Agrarian families
}

\author{
Nasreen Banu* and K. Yashoda \\ AICRP- H.Sc (All India Coordinated Research Project - Home Science), Human Development \\ Component, PGRC, PJTSAU (Professor Jayashankar Telangana State Agricultural \\ University), Rajendranagar, Hyderabad - 30, Telangana State, India \\ *Corresponding author
}

\section{A B S T R A C T}

\begin{tabular}{|l|}
\hline K e y w or d s \\
$\begin{array}{l}\text { Reproductive health, } \\
\text { Intervention programme, } \\
\text { Agrarian families }\end{array}$ \\
\hline Article Info \\
\hline $\begin{array}{l}\text { Accepted: } \\
15 \text { October } 2018 \\
\text { Available Online: } \\
10 \text { November } 2018\end{array}$ \\
\hline \hline
\end{tabular}

\section{Introduction}

India has 243 million adolescent people constituting about $21.4 \%$ of the country's total population. Adolescence is an important phase in life as it gives a second chance to improve the health and wellbeing of a child in their second decade as well as an opportunity to mitigate emergence of risk factors that may lead to diseases in adulthood.

The adolescence phase is marked by special characters like rapid physical growth, social and psychological maturity, beginning of menstrual cycle in girls and onset of reproduction cycle and development of adult mental processes and adult identity. During the process of transition to adulthood they face risk of acquiring reproductive and sexual health problems, psychiatric disorders and nutritional maladjustments. Appropriate intervention strategies will cherish the goal of a healthy adolescence.

Today's adolescents will determine the social structure, economic productivity, well-being of India, and also their experiences will influence the goal of achieving population stabilization as mentioned in the National population policy, 2000.In recognition of the 
importance of investing in adolescents health and India's commitment to achieve Millennium Developmental goals 4 and 5, several national policies and programmes are implemented now and then to address the needs of this group.

Adolescence is a critical period of human development often characterized by confusion, mixed messages from the adult population, exuberance and a penchant for experimentation, especially with drugs, alcohol and sex. According to Moore and Rosenthal (1993: ix), for most people, adolescence is a critical period in the upsurge of sex drives, the development of sexual values, and the initiation of sexual behavior.

There is consensus in the literature that adolescents engage in high risk sexual behaviors which predispose them to reproductive health problems. Indeed, as Dana Lear (1997:5) has noted "adolescents, and college students, are more likely to experiment sexually, often with multiple partners without using condoms on a regular basis".

It also drew on research elsewhere in Nigeria, which indicate that adolescents are sexually active but are often" extremely uninformed about their reproductive systems. This ignorance, more often than not, leads them to take risks which can lead to long term damage to their sexual and reproductive health" or even death (Madunagu, 1998:10).

\section{Operational definition}

\section{Knowledge}

Knowledge is a familiarity, awareness, or understanding of someone or something, such as facts, information, descriptions, or skills, which is acquired through experience or education by perceiving, discovering, or learning.
According to Webster's dictionary, knowledge is 'the fact or condition of knowing something with familiarity gained through experience or association'.

In practice, though, there are many possible, equally plausible definitions of knowledge. A frequently used definition of knowledge is "the ideas or understandings which an entity possesses that are used to take effective action to achieve the entity's goal (s).

\section{Agrarian families}

Families involved in Agriculture for their livelihood

\section{Intervention}

An intervention is a combination of programme elements or strategies designed to produce behavior changes or improve health status among individuals or an entire population.

\section{Reproductive health}

Reproductive health refers to the diseases, disorders and conditions that affect the functioning of the male and female reproductive systems during all stages of life. Reproductive health is a state of complete physical, mental and social well-being, and not merely the absence of reproductive disease or infirmity. Reproductive health deals with the reproductive processes, functions and system at all stages of life.

\section{Materials and Methods}

Sample was identified from the adopted villages (4) of Maheshwarammandal, RR District, Hyderabad, through field survey and focused group interviews with the help of the AWWs, ANMs, and Women Self-help Group leaders in the village. 
It's a quasi-experiment study. It is an empirical interventional study used to estimate the causal impact of an intervention on its target population without random assignment.

There were 110 adolescent girls in the age group of 16-19 years in the selected clusters of 4 villages namely Dubbacharla, Kollapadkal, Subhanpur and Pendyala, of Maheshwarammandaland 50 formed the sample for the present study. The following criterion was used to select the sample. Purposive sampling procedure was used.

\section{Criteria for sample selection}

Rural girls who were involved in Agriculture

Rural girls who were willing to participate in the project

\section{General objective}

Promoting Reproductive health Knowledge among Rural Adolescent girls from Agrarian families

\section{Specific objectives}

To find out the demographic profiles of the Selected sample

To find out the Knowledge levels of the Selected sample with regard to Reproductive health

To develop suitable IEC material for promoting Reproductive health among the selected sample

To conduct Knowledge based Intervention programme to the selected sample

To assess the impact of the Intervention programme on the Knowledge levels of the selected sample

\section{Research strategy adopted}

In order to achieve the above objectives, Knowledge based Intervention programmes were organized for the Rural Adolescent girls, using the developed IEC material.

\section{Research tools details}

SES scale developed by Aggrawal et al., (2005) was used to find out the SES of the Rural families. Scoring was given as per the norms provided in the manual.

It is a standardized scale, used to assess the family background information of the individuals, which includes parameters like educational and occupational status of parents, number of siblings, material possession, kind of locality, presence of farm animals, land holdings, number of earning members in the family etc. The scale categorizes the sample on: Upper High; High; Upper middle; Lower middle; Poor and Very poor Socio Economic Status.

Reproductive health awareness checklist was developed by AICRP-CD, Hyd Unit (2017) to find out the Knowledge levels of Married women with regard to Reproductive health issues. The Reliability Value of the checklist is: 0.81. The checklist comprises of 5 dimensions:

\section{Pubertal changes}

It is the First dimension and has 5 statements. It measures the knowledge levels of the sample with regard to pubertal changes.

\section{Menstruation related issues}

It is the Second dimension and has 5 statements. It measures the knowledge levels of the sample with regard to Menstrual problems. 
Signs and symptoms associated with menstruation

It is the Third dimension and has 10 statements.

Potential risks to health due to poor menstrual hygiene

It is the Fourth dimension and has 4 statements. It measures the knowledge levels of the sample with regard to problems related to poor menstrual hygiene.

\section{Transmission of HIV/AIDS}

It is the Fifth dimension and has 7 statements. It measures the knowledge levels of the sample with regard to awareness about transmission of HIV/AIDS and Preventive methods for HIV/AIDS.

There are all together 31 statements (all 5 dimensions). Each statement is arranged on 3 point scale i.e., aware is marked as 3 ; aware but not sure 2; Not sure as 1 . The total scores were further grouped as Low, Average and high. Higher the score, higher is the level of Knowledge in that particular dimension.

\section{Results and Discussion}

\section{Demographic data on rural adolescent girls}

There were 110 adolescent girls in the age group of 16-19 years in the selected clusters of 4 villages namely Dubbacharla, Kollapadkal, Subhanpur and Pendyala, of Maheshwarammandal and 50 formed the sample for the present study. The following criterion was used to select the sample. Purposive sampling procedure was used.

The table 1 depicts the Education wise distribution of Rural adolescent girls. Out of the total sample 50 , forty four percent of the sample completed Secondary school; 32\% completed Inter; $14 \%$ completed Primary school and $10 \%$ were illiterates.

The table 2 depicts the Occupation wise distribution of Rural adolescent girls. Out of the total sample 50, fifty percent of the sample were fully involved in agriculture; $40 \%$ were partially involved in agriculture; and 10\%\% were attending to household work.

The table 3 depicts the Socio Economic Status of Rural adolescent girls. Out of the total sample 50, more than half of $(72 \%)$ the sample were in lower middle income level; $18 \%$ were in upper middle income level and $10 \%$ were in poor economic status.

The table 4 traces the pretest scores of Adolescent girls with regard to Reproductive Health. The scale covers 5 dimensions.

With regard to Pubertal changes dimension, $30(60 \%)$ obtained Average scores; 12 (24\%) obtained High scores; and 8 (16\%) obtained low scores.

With regard to Menstruation dimension, 28 (56\%) obtained Average scores; 14 (28\%) obtained High scores; and 8 (16\%) obtained low scores.

With regard to Signs and Symptoms associated with menstruation dimension, 28 (56\%) obtained Average scores; 14 (28\%) obtained High scores; and 8 (16\%) obtained low scores.

With regard to Potential risks to health due to poor menstrual hygiene dimension, 25 (50\%) obtained low scores; 15 (30\%) obtained Average scores; and 10 (20\%) obtained High scores.

With regard to Transmission of HIV / AIDS dimension, 30 (60\%) obtained low scores; 12 
(24\%) obtained Average scores; and 8 (16\%) obtained High scores. Planning \& preparing educational material: Based on the bench mark issues and pre-assessment results, videos, brochures, leaflets, resource books and educational posters were planned / developed on selected thematic areas.

Educational posters mainly focused on: Adolescent Reproductive health; Balanced diet during Pregnancy; Birth control facts; Benefits of Breast feeding; Comprehensive nutrition; Condom use; Contraception choices; Healthy pregnancy; HIV prevention; Transmission of AIDs; Transmission of STI/ RTI; Reproductive rights; Reproductive problems; Reproductive health; Antenatal care; Immunization schedule; Menstrual hygiene; Menstrual problems; Menstrual education; Neonatal health; Sanitary napkin; STI symptoms. Videos mainly focused on: Effective Family planning methods; Importance of Breast feeding; Care during Pregnancy; Diet during Pregnancy; Immunization Schedule to be followed; Transmission of AIDs; Transmission of STI/ RTI; Importance of Reproductive Health; Antenatal Care; Reproductive rights; Menstrual problems; Danger symptoms of Pregnancy; HIV prevention; Healthy pregnancy; Reproductive Health; Maternal \& Child health services.

Table.1 Education wise distribution of the Selected sample $(\mathrm{N}=50)$

\begin{tabular}{|c|l|l|l|}
\hline Illiterate & $\begin{array}{l}\text { Primary } \\
\text { school }\end{array}$ & $\begin{array}{l}\text { Secondar } \\
\text { y school }\end{array}$ & Inter \\
\hline $\mathbf{N} \& \%$ & $\mathbf{N} \& \%$ & $\mathbf{N} \& \%$ & $\mathbf{N} \& \%$ \\
\hline $\mathbf{5 ( 1 0 \% )}$ & $\mathbf{7 ( 1 4 \% )}$ & $22(44 \%)$ & $16(32 \%)$ \\
\hline
\end{tabular}

Table.2 Occupation wise distribution of the Selected sample ( $\mathrm{N}=50)$

\begin{tabular}{l|l|l} 
Household work & $\begin{array}{c}\text { Fully involved in } \\
\text { agriculture (N \& \%) }\end{array}$ & $\begin{array}{l}\text { Partially involved in } \\
\text { agriculture (N \& \%) }\end{array}$ \\
\hline N \& \% &
\end{tabular}

\begin{tabular}{l|l|l}
\hline $5(10 \%)$ & $20(40 \%)$ & $25(50 \%)$
\end{tabular}

Table. 3 Socio Economic Status of the sample $(\mathrm{N}=50)$

\begin{tabular}{|l|c|c|}
\hline $\begin{array}{l}\text { Socio economic } \\
\text { status }\end{array}$ & $\begin{array}{c}\text { Score } \\
\text { Upper High }\end{array}$ & $\begin{array}{c}\text { Rural adolescent girls } \\
(\mathbf{N}=50)\end{array}$ \\
\hline High & $61-75$ & --- \\
\hline Upper middle & $46-60$ & --- \\
\hline Lower middle & $31-45$ & $\mathbf{9 6}(\mathbf{1 8 \%})$ \\
\hline Poor & $16-30$ & $\mathbf{5 ( 1 0 \% )})$ \\
\hline Very poor & $<15$ & ---- \\
\hline
\end{tabular}


Table.4 Reproductive health knowledge scores of rural adolescent girls ( $\mathrm{N}=50)$ - Pretest

\begin{tabular}{|c|c|c|c|}
\hline S. no & $\begin{array}{l}\text { Reproductive Health } \\
\text { awareness dimensions }\end{array}$ & Category \& Score & $\mathbf{N} \& \%$ \\
\hline \multirow[t]{3}{*}{1} & \multirow{3}{*}{ Pubertal changes (5) } & High (11-15) & $12(24 \%)$ \\
\hline & & Average (6-10) & $30(60 \%)$ \\
\hline & & Low $(<5)$ & $8(16 \%)$ \\
\hline \multirow[t]{3}{*}{2} & \multirow[t]{3}{*}{ Menstruation (5) } & High (11-15) & $14(28 \%)$ \\
\hline & & Average (6-10) & $28(56 \%)$ \\
\hline & & Low $(<5)$ & $8(16 \%)$ \\
\hline \multirow[t]{3}{*}{3} & \multirow{3}{*}{$\begin{array}{l}\text { Signs \& Symptoms } \\
\text { associated with } \\
\text { menstruation (10) }\end{array}$} & High (21-30) & $14(28 \%)$ \\
\hline & & Average (11-20) & $28(56 \%)$ \\
\hline & & Low $(<10)$ & $8(16 \%)$ \\
\hline \multirow[t]{3}{*}{4} & \multirow{3}{*}{$\begin{array}{l}\text { Potential risks to health } \\
\text { due to poor menstrual } \\
\text { hygiene (4) }\end{array}$} & High (9-12) & $10(20 \%)$ \\
\hline & & Average (5-8) & $15(30 \%)$ \\
\hline & & Low $(<4)$ & $25(50 \%)$ \\
\hline \multirow[t]{3}{*}{5} & \multirow{3}{*}{$\begin{array}{l}\text { Transmission of HIV / } \\
\text { AIDS (7) }\end{array}$} & High (19-27) & $8(16 \%)$ \\
\hline & & Average (10-18) & $12(24 \%)$ \\
\hline & & Low $(<9)$ & $30(60 \%)$ \\
\hline
\end{tabular}

Impact of Knowledge based Intervention: Reproductive health awareness among rural adolescent girls $(\mathbf{N}=\mathbf{5 0})$-Post test scores

\begin{tabular}{|c|c|c|c|}
\hline $\begin{array}{l}\text { S. } \\
\text { no }\end{array}$ & $\begin{array}{l}\text { Reproductive Health } \\
\text { awareness dimensions }\end{array}$ & Category \& Score & Post (N \& \%) \\
\hline \multirow[t]{3}{*}{1} & \multirow{3}{*}{$\begin{array}{l}\text { Awareness about Pubertal } \\
\text { changes (5) }\end{array}$} & High (11-15) & $32(64 \%)$ \\
\hline & & Average (6-10) & $15(30 \%)$ \\
\hline & & Low $(<5)$ & $3(6 \%)$ \\
\hline \multirow[t]{3}{*}{2} & \multirow{3}{*}{$\begin{array}{l}\text { Awareness about menstruation } \\
\text { (5) }\end{array}$} & High (11-15) & $33(66 \%)$ \\
\hline & & Average (6-10) & $14(28 \%)$ \\
\hline & & Low $(<5)$ & $3(6 \%)$ \\
\hline \multirow[t]{3}{*}{3} & \multirow{3}{*}{$\begin{array}{l}\text { Signs \& Symptoms associated } \\
\text { with menstruation (10) }\end{array}$} & High (21-30) & $28(56 \%)$ \\
\hline & & Average (11-20) & $20(40 \%)$ \\
\hline & & Low $(<10)$ & $2(4 \%)$ \\
\hline \multirow[t]{3}{*}{4} & \multirow{3}{*}{$\begin{array}{l}\text { Potential risks to health due to } \\
\text { poor menstrual hygiene (4) }\end{array}$} & High (9-12) & $29(58 \%)$ \\
\hline & & Average (5-8) & $18(36 \%)$ \\
\hline & & Low $(<4)$ & $3(6 \%)$ \\
\hline \multirow[t]{3}{*}{5} & \multirow{3}{*}{$\begin{array}{l}\text { Awareness about the } \\
\text { transmission of HIV / AIDS (7) }\end{array}$} & High (15-21) & $30(60 \%)$ \\
\hline & & Average (8-14) & $17(34 \%)$ \\
\hline & & Low $(<7)$ & $3(6 \%)$ \\
\hline
\end{tabular}


Reproductive health knowledge among Rural Adolescent girls ( $N=50)$

\begin{tabular}{|c|c|c|c|c|c|c|c|c|}
\hline \multirow[t]{2}{*}{ Variables } & \multicolumn{2}{|c|}{ Raw scores } & \multicolumn{2}{|c|}{ Mean } & \multicolumn{2}{|c|}{ SD } & \multirow{2}{*}{$\begin{array}{c}\text { Mean } \\
\text { differences } \\
\text { (P1-P) }\end{array}$} & \multirow[t]{2}{*}{ T values } \\
\hline & (P) & (P1) & (P) & (P1) & (P) & (P1) & & \\
\hline$\overline{I I}$ & 460 & 539 & 9.2 & 10.78 & 2.67 & 2.68 & 0.01 & $7.59 * *$ \\
\hline II & 451 & 575 & 9.02 & 11.5 & 2.48 & 2.95 & 0.47 & $4.37 * *$ \\
\hline III & 884 & 997 & 17.68 & 19.94 & 5.09 & 5.65 & 0.56 & $2.01 * *$ \\
\hline $\mathbf{I V}$ & 319 & 439 & 6.38 & 8.78 & 2.69 & 2.91 & 0.22 & $8.46 * *$ \\
\hline $\mathbf{V}$ & 478 & 750 & 9.56 & 15 & 3.34 & 3.56 & 0.22 & $1.15 * *$ \\
\hline GT & 2592 & 3300 & 51.84 & 66 & 14.53 & 16.58 & 2.05 & $4.15 * *$ \\
\hline
\end{tabular}
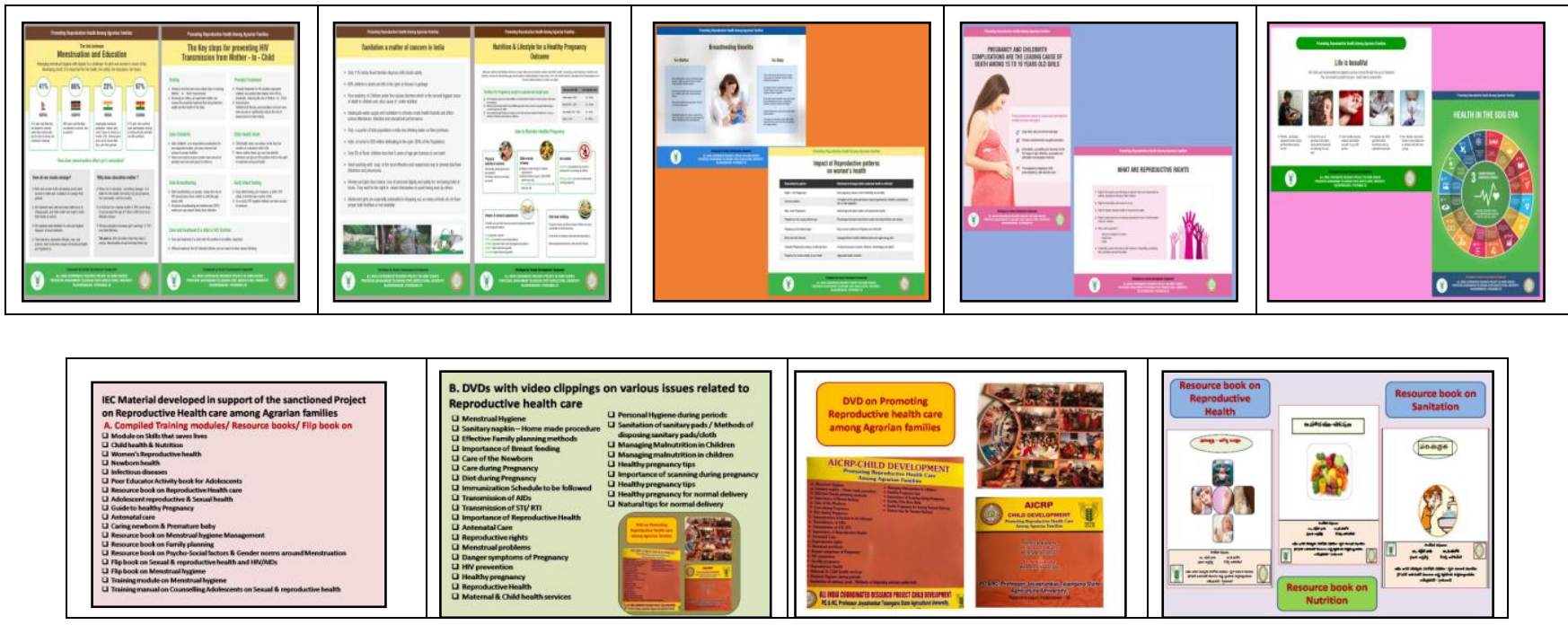

\section{Capacity building programmes}

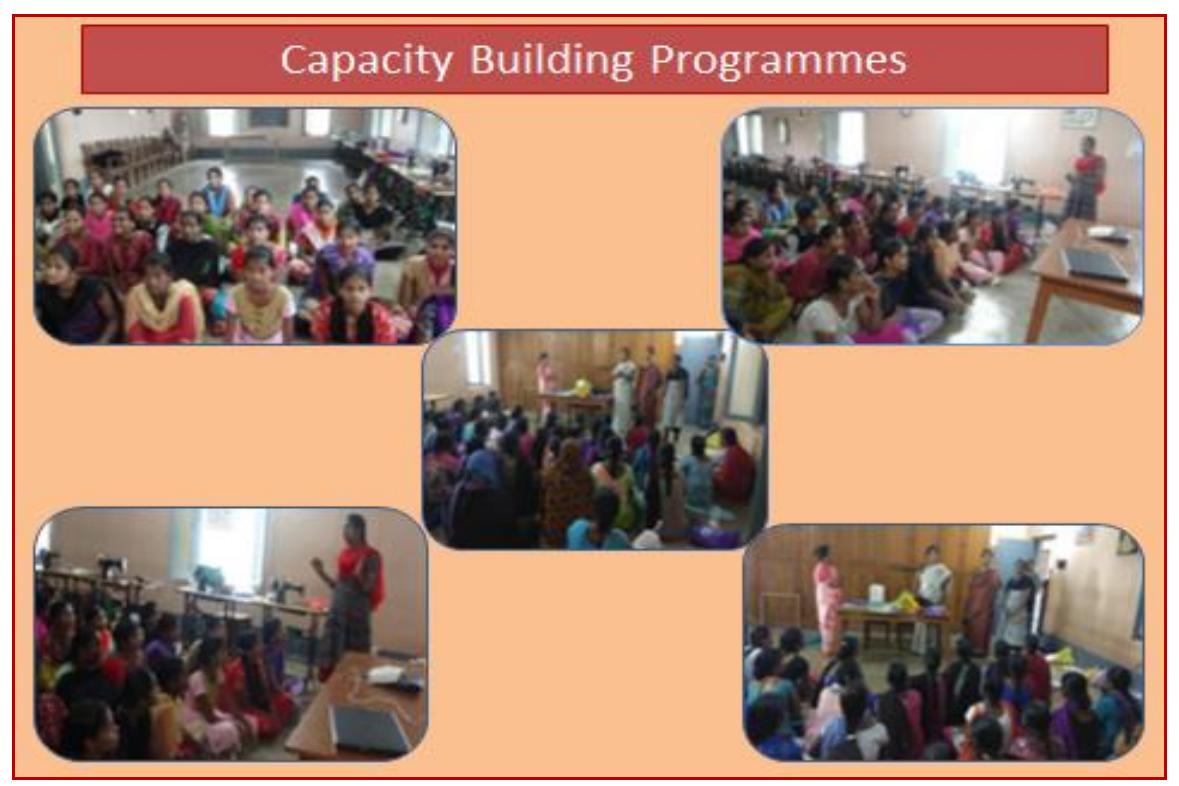



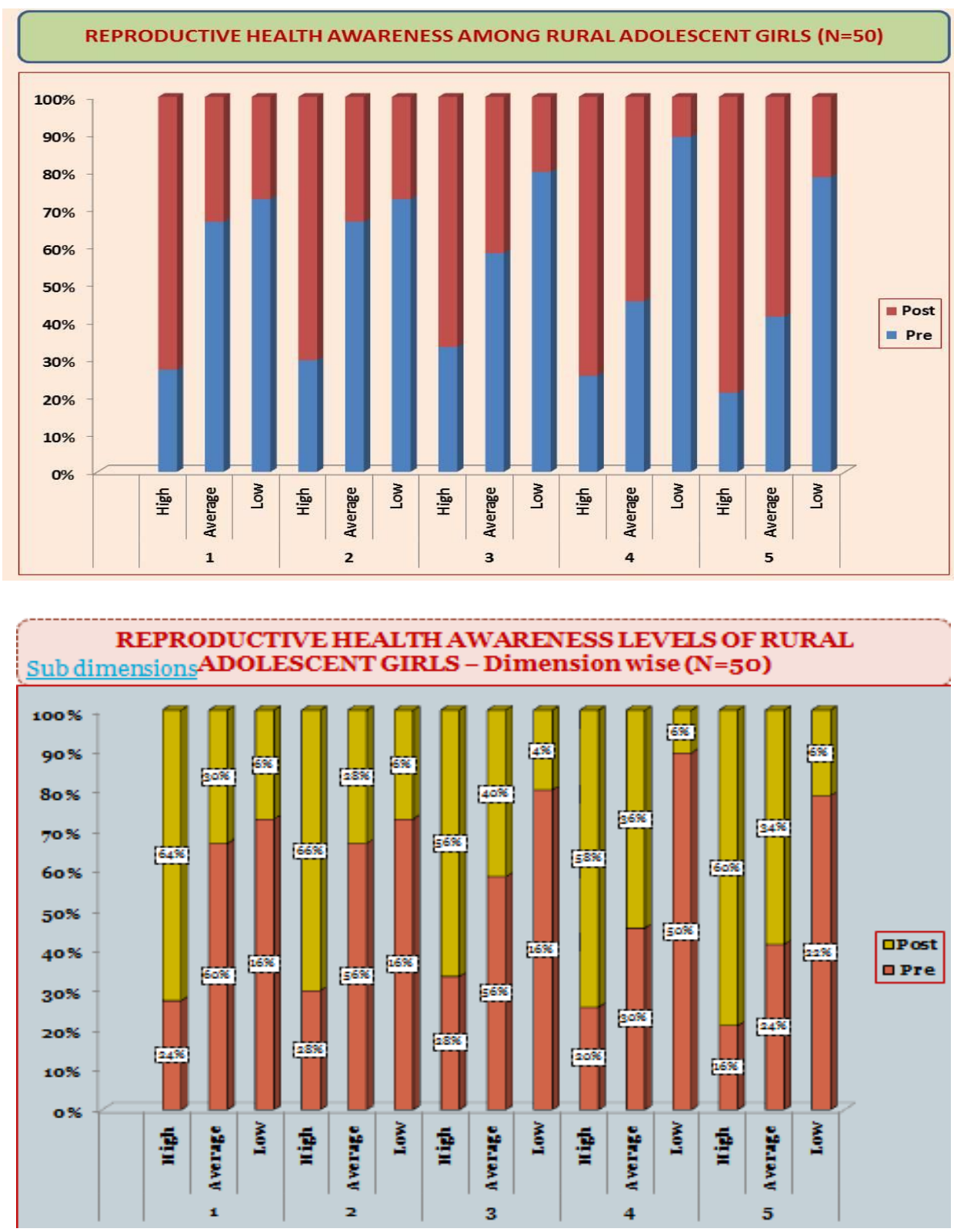

Some of the intervention strategies used for promoting Reproductive Health Knowledge among the sample was: group exercises, role plays, open ended stories, Brain storming, Group activities, Situation analysis, Case studies, Responding to real life situations and Group discussions etc.

Conducting programmes on Reproductive Health care: Knowledge based Capacity building programmes (10) were conducted for Rural Adolescent girls on issues concerning
Reproductive Health care. A comprehensive health education program was organized in 10 sessions for this group. Each session was of two hours duration conducted on three consecutive days. The training methods included a didactic lecture followed by interactive sessions with the Rural Adolescent girls to clarify doubts.

The table 4 traces the posttest scores of Adolescent girls with regard to Reproductive Health. The scale covers 5 dimensions. 
With regard to Pubertal changes dimension, 32 (64\%) obtained High scores; 15 (30\%) obtained Average scores; and $3(6 \%)$ obtained low scores.

With regard to Menstruation dimension, 33 (66\%) obtained High scores; 14 (28\%) obtained Average scores; and $3(6 \%)$ obtained low scores.

With regard to Signs \& Symptoms associated with menstruation dimension, 28 (56\%) obtained High scores; 20 (40\%) obtained Average scores; and 2 (4\%) obtained low scores.

With regard to Potential risks to health due to poor menstrual hygiene dimension, 29 (58\%) obtained High scores; 18(36\%) obtained Average scores; and $3(6 \%)$ obtained low scores.

With regard to Transmission of HIV / AIDS dimension, 30 (60\%) obtained High scores; 17 (34\%) obtained Average scores; and 3 $(6 \%)$ obtained low scores.

The table 4 presents the Pre \& Posttest (Raw scores, Means, SD and T values) Scores of Rural Adolescent girls with regard to Subdimensions under Reproductive health knowledge. The table shows the progressive increase in the total raw scores across pre-test to post-test, along with the increase in the mean differences, which shows the impact of intervention programme (Counseling sessions).

$T$ values between the two means of pre-test and post-test was found to be highly significant, as the calculated values were found to be greater than the tabulated value. The results reflect the effectiveness of Intervention programmes on the Psychological wellbeing of Rural Adolescent girls.
To achieve wholesome adolescent health, we need to have a multi-dimensional approach covering all the adolescent health problems with special emphasis on mental health, behaviour change communication towards healthy lifestyle and positive social environment to acquire life skills.

Adolescent friendly clinics need to be widely established throughout India and should achieve universal coverage. Screening of adolescent on regular basis could be an effective tool to control the existing disease and to update occurrence of any new diseases.

Empower and involve adolescents in decisions that affect them and facilitate them with every opportunity for developing into a successful adult. Offering such opportunities to the growing children gives them a chance to build a safe, happy, healthy and productive nation in the future.

\section{References}

Ayandele, 1974. Sexuality and Reproductive Health in Tertiary Educational Institutions in Nigeria, Research Report, MacArthur Foundation.

Ayu, 1985. The Challenges of Adolescent Reproductive Health in Nigeria Commissioned Paper for the project

Jega, 1994. "Premarital Sexual Relationships in Ghana" Health Policy and Planning 7(2): 135-143.

Madunagu, 1998. Sexual Communication in the Age of AIDS: The Construction of Risk and Trust among Young Adults. Social Science and Medicine, 41(9): 1311-1323

Moore and Rosenthal, 1993. "The Construction of Adolescence in a Changing World" Studies in Family Planning, 29(2): 137-153.

Onifade, 1999. Towards Understanding of Risk Behavior: an AIDS Risk 
Reduction Model. Health Education Quarterly 91:53-72.

Sai, 1995. Women and AIDS in Zimbabwe:

The Making of an Epidemic. Pp. 125-
139 Nancy Krieger and Glen Margo (Ed) AIDS: The Politics of Survival Amityville: Baywood.

\section{How to cite this article:}

Nasreen Banu and Yashoda, K. 2018. Impact of Intervention on the Reproductive Health Knowledge of Adolescent Girls from Agrarian families. Int.J.Curr.Microbiol.App.Sci. 7(11): 2143-2152. doi: https://doi.org/10.20546/ijcmas.2018.711.241 